\title{
The altered fate of aging satellite cells is determined by signaling and epigenetic changes
}

\author{
Maura H. Parker*
}

Clinical Research Division, Fred Hutchinson Cancer Research Center, Seattle, WA, USA

\section{Edited by:}

Lisa Maves, Seattle Children's

Research Institute, USA

Reviewed by:

Ian C. G. Weaver, Dalhousie

University, Canada

D Cornelison, University

of Missouri, USA

${ }^{*}$ Correspondence:

Maura H. Parker, Clinical

Research Division, Fred

Hutchinson Cancer Research

Center, 1100 Fairview Avenue

North, Seattle, WA 98109, USA

e-mail:mparker@fredhutch.org
Skeletal muscle is a striated tissue composed of multinucleated fibers that contract under the control of the somatic nervous system to direct movement. The stem cells of skeletal muscle, known as satellite cells, are responsible for muscle fiber growth, turnover, and regeneration. Satellite cells are activated and proliferate in response to stimuli, and simplistically, have two main fates-to repopulate the satellite cell niche, or differentiate to regenerate or repair muscle fibers. However, the ability to regenerate muscle and replace lost myofibers declines with age. This loss of function may be a result of extrinsic changes in the niche, such as alterations in signaling or modifications to the extracellular matrix. However, intrinsic epigenetic changes within satellite cells may also affect cell fate and cause a decline in regenerative capacity. This review will describe the mechanisms that regulate cell fate decisions in adult skeletal muscle, and how changes during aging affect muscle fiber turnover and regeneration.

Keywords: skeletal muscle, satellite cells, niche, aging, quiescence, senescence

\section{AGING, SARCOPENIA, AND THE SATELLITE CELL}

Aging is characterized by a time-dependent accumulation of cellular damage. Cells suffer damage as a result of chronological aging, as well as replicative aging, which occurs as cells proliferate in response to various stimuli. Stem cells are thought to be protected from the effects of aging by quiescence, a state of cellular hibernation which provides cushioning from the stresses associated with cell proliferation, thereby limiting cellular damage. However, quiescent cells are not dormant. Instead, quiescent stem cells actively maintain their state; they are poised for action, waiting for signals that activate proliferation. Aging is associated with the inability to maintain stem cell quiescence, which increases the chances of stem cell damage, and results in a loss of stem cell selfrenewal and regenerative capacity.

Aging is also associated with a gain of cellular senescence. Senescent cells are alive and metabolically active, but have lost the ability to divide. The primary purpose of senescence is to prevent propagation of damaged cells. Senescent cells are resistant to apoptosis, and are normally cleared by the immune system. Once cleared, tissue-specific repair mechanisms are activated and lost cells are replaced. During aging, senescent cells accumulate, which increases tissue inflammation, as senescent cells secrete pro-inflammatory cytokines, such as TNF $\alpha$ and IL-6. Thus, an increase in senescence, combined with a decrease in regenerative capacity, is predicted to result in a net loss of cells and/or tissue.

In skeletal muscle, aging is manifested as sarcopenia, the gradual loss of muscle mass and function in the absence of an attributable disease. Skeletal muscle is eventually replaced by fatty and fibrous tissue, which results in functional impairment of the muscle and physical disability. In the United States, sarcopenia occurs in approximately $45 \%$ of the population over the age of 60 , and upward of 50\% of muscle fibers are lost from limb muscles by the age of 80 (Janssen et al., 2004; Faulkner et al., 2007). However, sarcopenia can occur at any age as a result of disuse or malnutrition. In younger individuals, the loss of muscle mass is reversible, whereas in older or geriatric individuals, muscle loss appears to be irrecoverable.

The ability to generate skeletal muscle during post-natal growth and to regenerate skeletal muscle in adults is almost exclusively due to the action of Pax7-expressing satellite cells, the stem cells of skeletal muscle (Lepper et al., 2011; Murphy et al., 2011; Sambasivan et al., 2011). During the process of muscle regeneration, satellite cells are activated and proliferate, and adopt one of two cell fates: differentiation to generate or repair muscle fibers, or a return to quiescence to repopulate the satellite cell niche.

Given the role of satellite cells in post-natal muscle growth and adult muscle regeneration, it is reasonable to hypothesize that satellite cells are responsible for maintaining muscle mass and myonuclei number through aging. If true, then sarcopenia is predicted to be the result of a loss of satellite cell number, or a failure of satellite cells to function in aged individuals. Indeed, many studies have shown an age-related decline in the number of satellite cells and/or an age-related loss of satellite cell function (Roth et al., 2000; Conboy et al., 2003; Shefer et al., 2006; Day et al., 2010; Chakkalakal et al., 2012; Sousa-Victor et al., 2014). Moreover, transplantation of young satellite cells into the muscle of progeroid mice extends lifespan and ameliorates degenerative changes in skeletal muscle (Lavasani et al., 2012).

A more recent study challenges the notion that loss of satellite cells or satellite cell function is responsible for age-related sarcopenia (Fry et al., 2015). In this study, young mice were 
treated briefly with tamoxifen to deplete satellite cells by Pax7dependent activation of diphtheria toxin A (DTA) expression, and then allowed to age naturally. The results clearly show that satellite cell depletion does not accelerate age-related sarcopenia, but does affect the ability of skeletal muscle to respond to acute injury. This study highlights the need to better understand myonuclear turnover in adult muscle, and raises the question of whether satellite cells play a role in adult muscle maintenance.

A small population of satellite cells remains after tamoxifen treatment, and appears to increase in number over time in the gastrocnemius, tibialis anterior, and extensor digitorum longus muscles. Radiation-induced depletion of functional satellite cells in mice also results in survival of a small sub-population of satellite cells, which maintain the ability to contribute to repair and regeneration of skeletal muscle (Heslop et al., 2000). Moreover, transplant of a very small number of satellite cells, associated with a single muscle fiber, has the ability to generate a significant number of donor-derived muscle fibers, and contribute to the recipient satellite cell niche (Collins et al., 2005). Therefore, it is possible that the small number of satellite cells that remain in tamoxifen-treated mice provides enough cells to maintain muscle mass until other age-related changes occur, at which point loss of satellite cell function manifests as sarcopenia.

Age-related changes can be satellite cell-intrinsic or extrinsic. Satellite cells exist within a niche that consists of surrounding cells and the extracellular matrix (ECM), which provide biochemical and biophysical signals that direct regeneration and self-renewal. Age-related changes to the niche have the potential to affect satellite cell fate by altering environmental cues, resulting in aged satellite cells failing to re-enter quiescence, aberrantly entering senescence and/or failing to prevent fibrosis.

Satellite cells from aged and young muscle appear to proliferate ex vivo with similar rates (George et al., 2010; Alsharidah et al., 2013; Verdijk et al., 2014). The inability of aged satellite cells to show the effects of aging in a culture dish suggests that the aged muscle environment is to blame for the decline in regenerative capacity. However, studies with human cells suggest that culturing with $20 \%$ fetal calf serum masks differences between young and aged satellite cells, and demonstrate that culturing with human sera of the same age reveals a delayed response to activating stimuli and reduced proliferation (Barberi et al., 2013). Moreover, reduced regeneration in adult mice transplanted with FACS sorted geriatric satellite cells as compared to adult mice transplanted with adult satellite cells suggests a cell-intrinsic change that affects aged satellite cell function (Sousa-Victor et al., 2014).

Together, these data this suggests that satellite cell-intrinsic changes, combined with satellite cell-extrinsic changes within the niche alter cell fate decisions, and manifest as inefficient skeletal muscle repair, resulting in sarcopenia. This review will examine how satellite cell-extrinsic and satellite cell-intrinsic changes during aging affect satellite cell fate decisions and implicate the loss of satellite cell function as causative in sarcopenia.

\section{AGE-RELATED FIBROSIS AND SATELLITE CELL FATE}

During the later stages of normal regeneration, a sub-population of macrophages in the muscle secrete TGF $\beta$, which directs muscle- resident fibroblasts to secrete ECM proteins that reconstitute the basal lamina and the reticular lamina that surround muscle fibers. The ECM provides mechanical support and a scaffold to orient the fibers during regeneration (Sanes, 2003). Activation of TGF $\beta$ /activin signaling in cells specifically phosphorylates Smad2 and Smad3, stimulating nuclear localization and regulating gene expression. TGF $\beta$-mediated phosphorylation of Smad3 is specifically required for expression of collagen and ECM components in fibroblasts, and for activation and proliferation in satellite cells (Ge et al., 2011, 2012).

During aging, skeletal muscle fibers are progressively replaced by adipose and fibrotic tissue, which is exacerbated by injury (Brack et al., 2007; Paliwal et al., 2012). The formation of excessive connective tissue, also known as fibrosis, is a characteristic feature of sarcopenia. A change in intensity and duration of the macrophage response in aged skeletal muscle results in a higher level of TGF $\beta$ signaling in skeletal muscle (Zacks and Sheff, 1982; Carlson et al., 2008). This extends the phase of protein deposition by skeletal muscle fibroblasts, resulting in an increased level of ECM proteins and the presence of atypical types of collagen (Marshall et al., 1989; Alexakis et al., 2007). Moreover, less collagen turnover and more collagen cross-linking results in a densely packed lamina that increases muscle stiffness and potentially limits skeletal muscle function.

Increased TGF $\beta$ signaling inhibits satellite cell activation and proliferation (Allen and Boxhorn, 1987, 1989; Rathbone et al., 2011). Sustained TGF $\beta$ signaling in aged muscle is expected to decrease satellite cell proliferation, stimulate proliferation of fibroblasts in skeletal muscle, and increase expression of ECM proteins. Specifically, loss of satellite cell-derived signaling to muscle-resident fibroblasts relieves repression of collagen Ia1, collagen IIIa1, collagen VIia2, and fibronectin expression (Fry et al., 2014). Therefore, satellite cells, in addition to participating in the generation and repair of muscle fibers, are also responsible regulating ECM production and preventing fibrosis.

High levels of Wnt3a induce skeletal muscle fibrosis in mice, suggesting there may be a link between TGF $\beta$ and Wnt signaling in promoting fibrosis in aged muscle (Brack et al., 2007). Indeed, aged mice display an increase in the level of a serum factor that promotes Wnt activity, and this serum factor is postulated to promote excessive production of ECM proteins. This serum factor may be the complement protein, C1q, which can bind Fzd receptors and activate canonical Wnt signaling (Naito et al., 2012; Watanabe et al., 2014).

One study suggests that Wnt3a signaling stimulates canonical Wnt signaling and induces a change in cell fate, such that myogenic satellite cells are converted to the fibrogenic lineage (Brack et al., 2007). However, a separate study indicates that injection of a high level of Wnt3a into mouse skeletal muscle stimulates proliferation of a stromal cell population that produces collagen, resulting in replacement of adult skeletal muscle with fibrous tissue (Trensz et al., 2010). Importantly, both age- and diseaserelated fibrosis can be resolved by injection of DKK1, a Wnt signaling antagonist (Brack et al., 2007; Trensz et al., 2010).

The increase in fibrosis affects the ability of skeletal muscle to function. However, fibrosis also exacerbates the loss of satellite cell function by preventing satellite cell proliferation and 
self-renewal. Laminin, a primary protein component of the ECM, specifically interacts with integrin receptors on the surface of satellite cells. Satellite cell proliferation depends on a properly organized network of laminin within the basal lamina of the ECM (Ross et al., 2012). Moreover, the laminin-integrin interaction induces cell-intrinsic polarity, which is essential for asymmetric cell division and satellite cell self-renewal (Kuang et al., 2007; Goulas et al., 2012). Therefore, persistent TGF $\beta$ and Wnt signaling during aging leads to accumulation of skeletal muscle fibrosis, which disrupts basal lamina architecture, and reduces satellite cell proliferation and self-renewal.

\section{AGE-RELATED LOSS OF SATELLITE CELL SELF-RENEWAL SIGNALING AND SATELLITE CELL SELF-RENEWAL}

Impaired skeletal muscle regeneration in aged mice is due, in part, to loss of Notch signaling, and can be restored by forced activation of Notch in aged muscle, or parabiosis of aged mice with young mice (Conboy et al., 2003, 2005; Carlson et al., 2009). Similarly, skeletal muscle aging can be simulated in young mice by inhibition of Notch signaling after acute injury (Conboy and Rando, 2002). Satellite cell-specific deletion of RBP-J, the primary mediator of Notch signaling, in adult muscle results in loss of satellite cells and reduced regenerative capacity, as RBP-Jnull satellite cells spontaneously enter the cell cycle and immediately progress through differentiation without self-renewing (Bjornson et al., 2012; Mourikis et al., 2012). Therefore, agerelated loss of Notch signaling precludes satellite cell self-renewal, manifesting as a loss of satellite cells and impaired regenerative capacity.

Similarly, conditional deletion of RBP-J, in embryonic myogenic progenitors results in an absence of satellite cells in fetal muscle due to premature differentiation (Vasyutina et al., 2007). In a MyoD-null background, the loss of satellite cells is prevented, presumably due to a delay in myogenic differentiation (Brohl et al., 2012). Myogenic progenitor cells in RBP-J-null/MyoD-null mice are unable to home to the satellite cell niche, in part, due to loss of integrin $\alpha 7$ expression, which mediates the interaction between satellite cells and the basal lamina. Therefore, loss of Notch signaling in aging skeletal muscle, combined with alterations to basal lamina architecture as a result of fibrosis, disrupts satellite cell proliferation and self-renewal.

Diminished Notch activity in satellite cells is due, in part, to an age-related decrease in expression of the Notch receptor ligands, Jag1 and Dll1 (Conboy et al., 2003; Carey et al., 2007; Carlson et al., 2009). Reduced levels of Dll1 in mice results in severe muscle hypotrophy as a result of insufficient satellite cell proliferation (Schuster-Gossler et al., 2007). Jag1 is expressed in a subset of activated satellite cells, and generates asymmetry during cell division by activating Notch signaling in an adjacent receptorexpressing cell (Gnocchi et al., 2009). The Jag1 expressing cell expresses Numb, an antagonist of Notch signaling, and is fated to progress through commitment and differentiation; whereas the Numb-negative satellite cell responding to the Jag1 signal displays high Notch activity, and is fated for self-renewal (Conboy and Rando, 2002; Shinin et al., 2006). Loss of Jag1 expression in aging satellite cells prevents asymmetric Notch signaling, and therefore, prevents self-renewal.
Skeletal muscle regeneration has been postulated to be a balance between Notch and Wnt signaling, such that Notch is required for proliferation and self-renewal of satellite cells, and canonical Wnt signaling is required for induction of differentiation (Conboy and Rando, 2002; Conboy et al., 2003; Brack et al., 2007, 2008). However, tamoxifen-mediated deletion of $\beta$ catenin specifically in satellite cells suggests that canonical Wnt signaling is not required for differentiation during adult muscle regeneration (Murphy et al., 2014).

Wnts activate canonical and non-canonical pathways. In aging hematopoietic stem cells, a switch from canonical to noncanonical Wnt signaling causes a loss in stem-cell polarity and reduces regenerative potential (Florian et al., 2013). It is intriguing to hypothesize how a shift in which Wnt pathway is activated in aging could affect satellite cell fate and function. Given that noncanonical Wnt signaling in satellite cells specifically stimulates symmetric expansion, an age-related shift in Wnt signaling to the non-canonical pathway may impinge on satellite cell self-renewal, resulting in a loss of regenerative capacity (Le Grand et al., 2009). Therefore, persistent canonical Wnt signaling during aging may prevent satellite cell self-renewal, in addition to stimulating fibrosis.

Self-renewal of satellite cells requires asymmetric cell division and the ability of cells to re-enter and maintain quiescence. Increased expression of MyoD and Myf5 in aged muscle of rats and humans, in the absence of exercise or injury, suggests that satellite cells lose the ability to maintain quiescence during aging (Hameed et al., 2003; Edstrom and Ulfhake, 2005; Raue et al., 2006). Indeed, uninjured muscle from aged mice displays a greater percentage of actively proliferating MyoD-expressing satellite cells, as compared to the muscle of young mice (Chakkalakal et al., 2012). Reduced expression of p27, a cyclin-dependent kinase inhibitor (CDKi), and Sproutyl, a FGF signaling antagonist, is suggested to be the cause of spontaneous release from quiescence in aged satellite cells.

Spryl expression is restricted to non-cycling satellite cells, and is required for satellite cells to return to and maintain quiescence during regeneration (Shea et al., 2010). Long-term deletion of Spry1 in adult skeletal muscle satellite cells decreases the percentage of label-retaining cells, consistent with the loss of satellite cell quiescence observed in aging. Furthermore, Spry1-null satellite cells are unable to contribute to the generation of myonuclei or the renewal of quiescent satellite cells during skeletal muscle repair. Therefore, loss of Spryl expression in a subpopulation of aged satellite cells, combined with the increase in FGF2 expression in aged muscle fibers, drives satellite cell depletion by maintaining proliferation and preventing the return to quiescence. This is intriguing, as it suggests that the combination of cell autonomous changes (loss of Spryl expression) and changes to the niche (increased FGF2 expression) are involved in the loss of satellite cell self-renewal.

The FGF2-induced signal in satellite cells is mediated by many downstream targets, including p38 MAPKs (Cuadrado and Nebreda, 2010). In turn, activated p38 MAPKs phosphorylate a broad range of targets, including MyoD, NF- $\kappa \mathrm{B}, \mathrm{CREB}$, and STAT1/3. Conditional deletion of $\mathrm{p} 38 \alpha$ expression, or inhibition p38 $\alpha$ activity, promotes Pax7 expression and expansion of satellite 
cells, and prevents differentiation (Palacios et al., 2010; Brien et al., 2013). Activated and proliferating satellite cells display asymmetric distribution of activated phospho-p $38 \alpha / \beta(\mathrm{pp} 38 \alpha / \beta)$, such that cells expressing pp $38 \alpha / \beta$ co-express MyoD and progress through myogenic differentiation, whereas, pp38 $\alpha / \beta$-negative cells revert to quiescence (Jones et al., 2005; Troy et al., 2012).

Aging satellite cells display elevated pp38 $\alpha / \beta$ levels, combined with a loss of asymmetric distribution of $\mathrm{pp} 38 \alpha / \beta$, which correlates with a loss of self-renewal (Troy et al., 2012). Partial inhibition of $\mathrm{p} 38 \alpha / \beta$ activity restores self-renewal of aged satellite cells in vitro and reestablishes engraftment potential (Bernet et al., 2014; Cosgrove et al., 2014). Analogously, expression of a ligand-independent constitutively active form of FGFR1 also drives asymmetric localization of $\mathrm{pp} 38 \alpha / \beta$ in aged satellite cells, and permits satellite cell self-renewal (Bernet et al., 2014).

Like other signaling pathways, the $\mathrm{p} 38 \alpha / \beta$ pathway does not operate independently. Par- 3 , an evolutionarily conserved regulator of polarity, colocalizes with $\mathrm{pp} 38 \alpha / \beta$ in dividing satellite cells (Troy et al., 2012). In asymmetrically dividing radial glia, Par-3 is responsible for asymmetric localization of Mib to the apical daughter cell, which is fated for differentiation (Bultje et al., 2009; Dong et al., 2012). Mib is an ubiquitin ligase that regulates Notch ligand endocytosis in the apical cell, a process that is required for efficient activation of Notch signaling in the basal cell, which is destined for self-renewal. This is strikingly similar to satellite cells, in which high Notch activity marks satellite cells fated for selfrenewal.

Therefore, aging disrupts satellite cell self-renewal. Specifically, age-related cell extrinsic changes in expression of signaling ligands, combined with satellite cell-intrinsic alterations in the ability to appropriately respond to signals, disrupt asymmetric cell division and limit satellite cell self-renewal. The inability to self-renew results in a progressive loss of satellite cells, which diminishes competence to respond to acute injury and maintain muscle mass.

\section{EPIGENETICS AND SATELLITE CELL SELF-RENEWAL}

Activation of $\mathrm{p} 38 \alpha$ signaling directs satellite cells toward differentiation, and prevents self-renewal, by repressing expression of Pax7 and Notch1 through localized targeting of Ezh2, a histone methyltransferase, and DNMT3b, a DNA methyltransferase, to each gene (Acharyya et al., 2010; Palacios et al., 2010). Ezh2 is a component of the polycomb repressive complex (PRC2), which in combination with PRC1, establishes and stabilizes repression through post-translational modification of histones.

Post-translation modification of histones is an epigenetic change that marks genes as active or inactive. Methylation of lysine $4(\mathrm{H} 3 \mathrm{~K} 4 \mathrm{me} 3)$ of histone $\mathrm{H} 3$ is generally associated with active chromatin, while methylation of lysine 27 (H3K27me3) is linked with repressed chromatin (Dilworth and Blais, 2011). A bivalent state can exist in which histone $\mathrm{H} 3$ is methylated at both lysine 4 and lysine 27. Notably, the repressive H3K27me3 mark is dominant over the active $\mathrm{H} 3 \mathrm{~K} 4 \mathrm{me} 3 \mathrm{mark}$, and is heritably transmitted to daughter cells (Barski et al., 2007).

Genome-wide analysis of chromatin in young and aged quiescent satellite cells demonstrated that the level of H3K4me3 histone marking was comparable between young and old satellite cells; however, H3K27me3 accumulates and spreads with age in quiescent satellite cells (Liu et al., 2013). Notably, 30\% of genes that acquire $\mathrm{H} 3 \mathrm{~K} 27 \mathrm{me} 3$ were not expressed in either young or old quiescent satellite cells, and less than $0.5 \%$ of genes are marked solely by $\mathrm{H} 3 \mathrm{~K} 27 \mathrm{me} 3$. It is difficult to correlate the global change in $\mathrm{H} 3 \mathrm{~K} 27 \mathrm{me} 3$ in satellite cells with aging. However, this gain of H3K27me3 marks may reflect a loss of potential, as low levels of $\mathrm{H} 3 \mathrm{~K} 27 \mathrm{me} 3$ is associated with pluripotency (Mikkelsen et al., 2007; Marks et al., 2012).

The increase in $\mathrm{H} 3 \mathrm{~K} 27 \mathrm{me} 3$ in aging is thought to be linked to a redistribution of PRC1 and PRC2 complexes. Bivalent domains can be segregated into two types - those that are bound by PRC1 and PRC2, and those that are bound only by PRC2 (Ku et al., 2008). Binding of PRC1 more effectively retains the H3K27me3 mark, thereby maintaining repression. Specifically, PRC1 stabilizes bivalent domains, and reinforces the ability of stem cells and progenitor cells to retain cell fate choices, including self-renewal (Oguro et al., 2010). Therefore, loss of PRC1 is expected to drive satellite cells out of quiescence and prevent satellite cell selfrenewal. Indeed, mice lacking Bmil, a component of the PRC1 complex, show reduced numbers of $\mathrm{Pax}^{+} \mathrm{Myf5} 5^{-}$satellite stem cells, and an increase in $\mathrm{Pax}^{+} \mathrm{Myf5}^{+}$and $\mathrm{MyoD}^{+}$committed satellite cells, reminiscent of the age-related loss of quiescence (Robson et al., 2011). Moreover, Bmil-null mice display a delay in regeneration upon injury. Therefore, cell-extrinsic changes to signaling and cell-intrinsic changes in signal response during aging can produce long-term and heritable results by inducing epigenetic changes.

\section{AGE-RELATED INDUCTION OF SENESCENCE}

Senescent cells are alive and metabolically active, but have lost the ability to divide. Senescence can be induced through several mechanisms, but is most closely associated with aging. The primary purpose of senescence is to prevent propagation of damaged cells. Senescent cells are cleared by the immune system, and lost cells are replaced by tissue-specific repair mechanisms. Agerelated changes in the immune system, combined with an increase in the number of senescent cells, may result in the accumulation of senescent cells, which secrete cytokines and other molecules that induce inflammation and inhibit tissue regeneration (Kuilman et al., 2008; Rodier and Campisi, 2011).

Recent studies indicate that satellite cells enter senescence with advanced age. Sousa-Victor et al. (2014) compared adult (5-6 mo), old (20-24 mo), and geriatric (28-32 mo) mice, and showed that old and geriatric mice display a reduced number of satellite cells, but only satellite cells in geriatric mice display a reduced proliferative response. Moreover, skeletal muscle regeneration was marginally reduced in old mice, but is more markedly diminished in geriatric mice. Transplantation of FACS sorted cells from adult, old, and geriatric mice into young mice clearly showed a significant reduction in regenerative potential only in geriatric cells, indicating a cell-intrinsic loss of regenerative capacity with aging.

Mouse and human geriatric satellite cells express $\mathrm{p} 16^{\mathrm{INK} 4 \mathrm{~A}}$, and display classic markers of senescence (Sousa-Victor et al., 2014). Silencing of $\mathrm{p} 16^{\mathrm{INK} 4 \mathrm{~A}}$ expression in geriatric mouse satellite cells restores regeneration-induced activation of proliferation and reversible quiescence. In parallel experiments, ectopic 
expression of $\mathrm{p} 16^{\mathrm{INK} 4 \mathrm{~A}}$ prevents activation of satellite cells after injury of young muscle. These data suggest that expression of p16 $6^{\mathrm{INK} 4 \mathrm{~A}}$ in geriatric satellite cells induces cellular senescence and is responsible for the aging phenotype in skeletal muscle. However, a mild and systemic increase in $\mathrm{p} 16^{\mathrm{INK} 4 \mathrm{~A}}$ expression extends longevity in mice, suggesting the dosage of $\mathrm{p} 16^{\mathrm{INK} 4 \mathrm{~A}}$ may be important for determining effect (Matheu et al., 2007, 2009).

In young cells, the combined action of PRC1 and PRC2 represses $\mathrm{p} 16^{\mathrm{INK} 4 \mathrm{~A}}$ expression through maintenance of H3K27me3 marks, thereby preventing cellular senescence (Jacobs et al., 1999; Bracken et al., 2007; Margueron and Reinberg, 2011). Geriatric satellite cells display an increase in expression of genes normally regulated by PRC1 and PRC2, suggesting that satellite cells may exhibit age-related epigenetic changes. Bmil, a component of the PRC1 complex, represses expression of $\mathrm{p} 16^{\mathrm{INK} 4 \mathrm{~A}}$, and has been suggested to play an important role in delaying aging by preventing cellular senescence (Jacobs et al., 1999). Therefore, if Bmil expression or function is lost with aging, satellite cells would be expected to lose the ability to maintain quiescence and eventually senesce.

Notch signaling positively regulates expression of Bmil, suggesting that loss of Notch signaling in aging satellite cells may reduce Bmil expression, de-repress the $\mathrm{p} 16^{\mathrm{INK} 4 \mathrm{~A}}$ locus, resulting in satellite cell senescence (Fan et al., 2010; Schaller et al., 2010; Sousa-Victor et al., 2014). Indeed, deletion of Bmil in young satellite cells leads to de-repression of the $\mathrm{p} 16^{\mathrm{INK} 4 \mathrm{~A}}$ locus, increased expression of $\mathrm{p} 16^{\mathrm{INK} 4 \mathrm{~A}}$, which leads to a senescent-like state in young cells and prevents these cells from participating in regeneration (Robson et al., 2011). Moreover, reduced Notch signaling in aged satellite cells allows TGF $\beta$-stimulated phosphorylation of Smad3 to activate expression of CDK inhibitors (CDKis; Beggs et al., 2004; Carlson et al., 2008). Therefore, persistent TGF $\beta$ signaling and loss of Notch signaling during skeletal muscle aging increases fibrosis, inhibits satellite cell proliferation, and induces satellite cell senescence.

\section{CONCLUSIONS AND PERSPECTIVES}

Age-related changes within satellite cells and to their niche limit cell fate and function. In the aged niche, satellite cells shift from a poised, quiescent state to the active state in the absence of a regenerative signal. Persistent TGF $\beta$-and Wnt-dependent accumulation of skeletal muscle fibrosis disrupts basal lamina architecture. Dysregulation of Wnt, Notch, FGF, and $\mathrm{p} 38 \alpha / \beta$ signaling results in a loss of cell polarity, and prevents asymmetric cell division. Age-related loss of Notch activity and persistence of TGF $\beta$ activity induce epigenetic changes that de-repress the CDKN2A locus and induce expression of $\mathrm{p} 16^{\mathrm{INK} 4 \mathrm{~A}}$. These changes combine to drive satellite cells away from normal cell fate decisionsdifferentiation and self-renewal-toward age-realted senescence. In genome-wide association studies, the $\mathrm{p} 16^{\mathrm{INK} 4 \mathrm{~A}}$ locus is genetically linked to the highest number of age-associated pathologies.

Restoring regenerative capacity to aged skeletal muscle could be as simple as replacing aged satellite cells with young satellite cells, and/or modifying signaling pathways to maintain reversible quiescence. However, it appears that the effects of aging culminate in epigenetics and expression of $\mathrm{p} 16^{\mathrm{INK} 4 \mathrm{~A}}$. Global demethylation of DNA occurs after fertilization and is required for pluripotency
(Guo et al., 2014; Smith et al., 2014). This suggests that skeletal muscle aging may be reversed simply by manipulating the epigenetic memory of satellite cells, and resetting the aging clock to zero.

\section{REFERENCES}

Acharyya, S., Sharma, S. M., Cheng, A. S., Ladner, K. J., He, W., Kline, W., et al. (2010). TNF inhibits Notch-1 in skeletal muscle cells by Ezh2 and DNA methylation mediated repression: implications in duchenne muscular dystrophy. PLoS ONE 5:e12479. doi: 10.1371/journal.pone.0012479

Alexakis, C., Partridge, T., and Bou-Gharios, G. (2007). Implication of the satellite cell in dystrophic muscle fibrosis: a self-perpetuating mechanism of collagen overproduction. Am. J. Physiol. Cell Physiol. 293, C661-C669. doi: 10.1152/ajpcell.00061.2007

Allen, R. E., and Boxhorn, L. K. (1987). Inhibition of skeletal muscle satellite cell differentiation by transforming growth factor-beta. J. Cell. Physiol. 133, 567572. doi: 10.1002/jcp.1041330319

Allen, R. E., and Boxhorn, L. K. (1989). Regulation of skeletal muscle satellite cell proliferation and differentiation by transforming growth factor-beta, insulinlike growth factor I, and fibroblast growth factor. J. Cell. Physiol. 138, 311-315. doi: $10.1002 /$ jcp. 1041380213

Alsharidah, M., Lazarus, N. R., George, T. E., Agley, C. C., Velloso, C. P., and Harridge, S. D. (2013). Primary human muscle precursor cells obtained from young and old donors produce similar proliferative, differentiation and senescent profiles in culture. Aging Cell 12, 333-344. doi: 10.1111/acel.12051

Barberi, L., Scicchitano, B. M., De, R. M., Bigot, A., Duguez, S., Wielgosik, A., et al. (2013). Age-dependent alteration in muscle regeneration: the critical role of tissue niche. Biogerontology 14, 273-292. doi: 10.1007/s10522-013-9429-4

Barski, A., Cuddapah, S., Cui, K., Roh, T. Y., Schones, D. E., Wang, Z., et al. (2007). High-resolution profiling of histone methylations in the human genome. Cell 129, 823-837. doi: 10.1016/j.cell.2007.05.009

Beggs, M. L., Nagarajan, R., Taylor-Jones, J. M., Nolen, G., Macnicol, M., and Peterson, C. A. (2004). Alterations in the TGFbeta signaling pathway in myogenic progenitors with age. Aging Cell 3, 353-361. doi: 10.1111/j.1474-9728. 2004.00135.x

Bernet, J. D., Doles, J. D., Hall, J. K., Kelly, T. K., Carter, T. A., and Olwin, B. B. (2014). p38 MAPK signaling underlies a cell-autonomous loss of stem cell self-renewal in skeletal muscle of aged mice. Nat. Med. 20, 265-271. doi: 10.1038/nm.3465

Bjornson, C. R., Cheung, T. H., Liu, L., Tripathi, P. V., Steeper, K. M., and Rando, T. A. (2012). Notch signaling is necessary to maintain quiescence in adult muscle stem cells. Stem Cells 30, 232-242. doi: 10.1002/stem.773

Brack, A. S., Conboy, I. M., Conboy, M. J., Shen, J., and Rando, T. A. (2008). A temporal switch from notch to Wnt signaling in muscle stem cells is necessary for normal adult myogenesis. Cell Stem Cell 2, 50-59. doi: 10.1016/j.stem.2007. 10.006

Brack, A. S., Conboy, M. J., Roy, S., Lee, M., Kuo, C. J., Keller, C., et al. (2007). Increased Wnt signaling during aging alters muscle stem cell fate and increases fibrosis. Science 317, 807-810. doi: 10.1126/science.1144090

Bracken, A. P., Kleine-Kohlbrecher, D., Dietrich, N., Pasini, D., Gargiulo, G., Beekman, C., et al. (2007). The polycomb group proteins bind throughout the INK4A-ARF locus and are disassociated in senescent cells. Genes Dev. 21, 525530. doi: 10.1101/gad.415507

Brien, P., Pugazhendhi, D., Woodhouse, S., Oxley, D., and Pell, J. M. (2013). p38 $\alpha$ MAPK regulates adult muscle stem cell fate by restricting progenitor proliferation during postnatal growth and repair. Stem Cells 31, 1597-1610. doi: 10.1002/stem.1399

Brohl, D., Vasyutina, E., Czajkowski, M. T., Griger, J., Rassek, C., Rahn, H. P., et al. (2012). Colonization of the satellite cell niche by skeletal muscle progenitor cells depends on Notch signals. Dev. Cell 23, 469-481. doi: 10.1016/j.devcel. 2012.07.014

Bultje, R. S., Castaneda-Castellanos, D. R., Jan, L. Y., Jan, Y. N., Kriegstein, A. R., and Shi, S. H. (2009). Mammalian Par3 regulates progenitor cell asymmetric division via notch signaling in the developing neocortex. Neuron 63, 189-202. doi: 10.1016/j.neuron.2009.07.004

Carey, K. A., Farnfield, M. M., Tarquinio, S. D., and Cameron-Smith, D. (2007). Impaired expression of Notch signaling genes in aged human skeletal muscle. J. Gerontol. A Biol. Sci. Med. Sci. 62, 9-17. doi: 10.1093/gerona/62.1.9 
Carlson, M. E., Hsu, M., and Conboy, I. M. (2008). Imbalance between pSmad3 and Notch induces CDK inhibitors in old muscle stem cells. Nature 454, 528 532. doi: $10.1038 /$ nature 07034

Carlson, M. E., Suetta, C., Conboy, M. J., Aagaard, P., Mackey, A., Kjaer, M., et al. (2009). Molecular aging and rejuvenation of human muscle stem cells. EMBO Mol. Med. 1, 381-391. doi: 10.1002/emmm.200900045

Chakkalakal, J. V., Jones, K. M., Basson, M. A., and Brack, A. S. (2012). The aged niche disrupts muscle stem cell quiescence. Nature 490, 355-360. doi: 10.1038 /nature 11438

Collins, C. A., Olsen, I., Zammit, P. S., Heslop, L., Petrie, A., Partridge, T. A., et al. (2005). Stem cell function, self-renewal, and behavioral heterogeneity of cells from the adult muscle satellite cell niche. Cell 122, 289-301. doi: 10.1016/ j.cell.2005.05.010

Conboy, I. M., Conboy, M. J., Smythe, G. M., and Rando, T. A. (2003). Notchmediated restoration of regenerative potential to aged muscle. Science 302, 1575-1577. doi: 10.1126/science.1087573

Conboy, I. M., Conboy, M. J., Wagers, A. J., Girma, E. R., Weissman, I. L., and Rando, T. A. (2005). Rejuvenation of aged progenitor cells by exposure to a young systemic environment. Nature 433, 760-764. doi: 10.1038/nature 03260

Conboy, I. M., and Rando, T. A. (2002). The regulation of Notch signaling controls satellite cell activation and cell fate determination in postnatal myogenesis. Dev. Cell 3, 397-409. doi: 10.1016/S1534-5807(02)00254-X

Cosgrove, B. D., Gilbert, P. M., Porpiglia, E., Mourkioti, F., Lee, S. P., Corbel, S. Y., et al. (2014). Rejuvenation of the muscle stem cell population restores strength to injured aged muscles. Nat. Med. 20, 255-264. doi: 10.1038/nm.3464

Cuadrado, A., and Nebreda, A. R. (2010). Mechanisms and functions of p38 MAPK signalling. Biochem. J. 429, 403-417. doi: 10.1042/BJ20100323

Day, K., Shefer, G., Shearer, A., and Yablonka-Reuveni, Z. (2010). The depletion of skeletal muscle satellite cells with age is concomitant with reduced capacity of single progenitors to produce reserve progeny. Dev. Biol. 340, 330-343. doi: 10.1016/j.ydbio.2010.01.006

Dilworth, F. J., and Blais, A. (2011). Epigenetic regulation of satellite cell activation during muscle regeneration. Stem Cell Res. Ther. 2, 18. doi: 10.1186/scrt59

Dong, Z., Yang, N., Yeo, S. Y., Chitnis, A., and Guo, S. (2012). Intralineage directional Notch signaling regulates self-renewal and differentiation of asymmetrically dividing radial glia. Neuron 74, 65-78. doi: 10.1016/j.neuron.2012.01.031

Edstrom, E., and Ulfhake, B. (2005). Sarcopenia is not due to lack of regenerative drive in senescent skeletal muscle. Aging Cell 4, 65-77. doi: 10.1111/j.1474-9728. 2005.00145.x

Fan, X., Khaki, L., Zhu, T. S., Soules, M. E., Talsma, C. E., Gul, N., et al. (2010). NOTCH pathway blockade depletes CD133-positive glioblastoma cells and inhibits growth of tumor neurospheres and xenografts. Stem Cells 28, 5-16. doi: 10.1002/stem. 254

Faulkner, J. A., Larkin, L. M., Claflin, D. R., and Brooks, S. V. (2007). Age-related changes in the structure and function of skeletal muscles. Clin. Exp. Pharmacol. Physiol. 34, 1091-1096. doi: 10.1111/j.1440-1681.2007.04752.x

Florian, M. C., Nattamai, K. J., Dorr, K., Marka, G., Uberle, B., Vas, V., et al. (2013). A canonical to non-canonical Wnt signalling switch in haematopoietic stem-cell ageing. Nature 503, 392-396. doi: 10.1038/nature12631

Fry, C. S., Lee, J. D., Jackson, J. R., Kirby, T. J., Stasko, S. A., Liu, H., et al. (2014). Regulation of the muscle fiber microenvironment by activated satellite cells during hypertrophy. FASEB J. 28, 1654-1665. doi: 10.1096/fj.13-239426

Fry, C. S., Lee, J. D., Mula, J., Kirby, T. J., Jackson, J. R., Liu, F., et al. (2015). Inducible depletion of satellite cells in adult, sedentary mice impairs muscle regenerative capacity without affecting sarcopenia. Nat. Med. 21, 76-80. doi: 10.1038/ nm. 3710

Ge, X., McFarlane, C., Vajjala, A., Lokireddy, S., Ng, Z. H., Tan, C. K., et al. (2011). Smad3 signaling is required for satellite cell function and myogenic differentiation of myoblasts. Cell Res. 21, 1591-1604. doi: 10.1038/cr.2011.72

Ge, X., Vajjala, A., McFarlane, C., Wahli, W., Sharma, M., and Kambadur, R. (2012). Lack of Smad3 signaling leads to impaired skeletal muscle regeneration. Am. J. Physiol. Endocrinol. Metab. 303, E90-E102. doi: 10.1152/ajpendo.00113.2012

George, T., Velloso, C. P., Alsharidah, M., Lazarus, N. R., and Harridge, S. D. (2010). Sera from young and older humans equally sustain proliferation and differentiation of human myoblasts. Exp. Gerontol. 45, 875-881. doi: 10.1016/j.exger. 2010.07.006

Gnocchi, V. F., White, R. B., Ono, Y., Ellis, J. A., and Zammit, P. S. (2009). Further characterisation of the molecular signature of quiescent and activated mouse muscle satellite cells. PLoS ONE 4:e5205. doi: 10.1371/journal.pone.0005205
Goulas, S., Conder, R., and Knoblich, J. A. (2012). The par complex and integrins direct asymmetric cell division in adult intestinal stem cells. Cell Stem Cell 11, 529-540. doi: 10.1016/j.stem.2012.06.017

Guo, H., Zhu, P., Yan, L., Li, R., Hu, B., Lian, Y., et al. (2014). The DNA methylation landscape of human early embryos. Nature 511, 606-610. doi: 10.1038/ nature 13544

Hameed, M., Orrell, R. W., Cobbold, M., Goldspink, G., and Harridge, S. D. (2003). Expression of IGF-I splice variants in young and old human skeletal muscle after high resistance exercise. J. Physiol. 547, 247-254. doi: 10.1113/jphysiol.2002.032136

Heslop, L., Morgan, J. E., and Partridge, T. A. (2000). Evidence for a myogenic stem cell that is exhausted in dystrophic muscle. J. Cell Sci. 113, 2299-2308.

Jacobs, J. J., Kieboom, K., Marino, S., DePinho, R. A., and van, L. M. (1999). The oncogene and Polycomb-group gene bmi-1 regulates cell proliferation and senescence through the ink4a locus. Nature 397, 164-168. doi: 10.1038/16476

Janssen, I., Shepard, D. S., Katzmarzyk, P. T., and Roubenoff, R. (2004). The healthcare costs of sarcopenia in the United States. J. Am. Geriatr. Soc. 52, 80-85. doi: 10.1111/j.1532-5415.2004.52014.x

Jones, N. C., Tyner, K. J., Nibarger, L., Stanley, H. M., Cornelison, D. D., Fedorov, Y. V., et al. (2005). The p38 $\alpha / \beta$ MAPK functions as a molecular switch to activate the quiescent satellite cell. J. Cell Biol. 169, 105-116. doi: 10.1083/jcb. 200408066

Ku, M., Koche, R. P., Rheinbay, E., Mendenhall, E. M., Endoh, M., Mikkelsen, T. S., et al. (2008). Genomewide analysis of PRC1 and PRC2 occupancy identifies two classes of bivalent domains. PLoS Genet. 4:e1000242. doi: 10.1371/journal. pgen.1000242

Kuang, S., Kuroda, K., Le, G. F., and Rudnicki, M. A. (2007). Asymmetric selfrenewal and commitment of satellite stem cells in muscle. Cell 129, 999-1010. doi: 10.1016/j.cell.2007.03.044

Kuilman, T., Michaloglou, C., Vredeveld, L. C., Douma, S., van, D. R., Desmet, C. J., et al. (2008). Oncogene-induced senescence relayed by an interleukindependent inflammatory network. Cell 133, 1019-1031. doi: 10.1016/j.cell.2008. 03.039

Lavasani, M., Robinson, A. R., Lu, A., Song, M., Feduska, J. M., Ahani, B., et al. (2012). Muscle-derived stem/progenitor cell dysfunction limits healthspan and lifespan in a murine progeria model. Nat. Commun. 3, 608. doi: 10.1038/ ncomms 1611

Le Grand, F., Jones, A. E., Seale, V., Scime, A., and Rudnicki, M. A. (2009). Wnt7a activates the planar cell polarity pathway to drive the symmetric expansion of satellite stem cells. Cell Stem Cell 4, 535-547. doi: 10.1016/j.stem.2009.03.013

Lepper, C., Partridge, T. A., and Fan, C. M. (2011). An absolute requirement for Pax7-positive satellite cells in acute injury-induced skeletal muscle regeneration. Development 138, 3639-3646. doi: 10.1242/dev.067595

Liu, L., Cheung, T. H., Charville, G. W., Hurgo, B. M., Leavitt, T., Shih, J., et al. (2013). Chromatin modifications as determinants of muscle stem cell quiescence and chronological aging. Cell Rep. 4, 189-204. doi: 10.1016/j.celrep. 2013.05.043

Margueron, R., and Reinberg, D. (2011). The Polycomb complex PRC2 and its mark in life. Nature 469, 343-349. doi: 10.1038/nature09784

Marks, H., Kalkan, T., Menafra, R., Denissov, S., Jones, K., Hofemeister, H., et al. (2012). The transcriptional and epigenomic foundations of ground state pluripotency. Cell 149, 590-604. doi: 10.1016/j.cell.2012.03.026

Marshall, P. A., Williams, P. E., and Goldspink, G. (1989). Accumulation of collagen and altered fiber-type ratios as indicators of abnormal muscle gene expression in the $\mathrm{mdx}$ dystrophic mouse. Muscle Nerve 12, 528-537. doi: $10.1002 /$ mus. 880120703

Matheu, A., Maraver, A., Collado, M., Garcia-Cao, I., Canamero, M., Borras, C., et al. (2009). Anti-aging activity of the Ink4/Arf locus. Aging Cell 8, 152-161. doi: 10.1111/j.1474-9726.2009.00458.x

Matheu, A., Maraver, A., Klatt, P., Flores, I., Garcia-Cao, I., Borras, C., et al. (2007). Delayed ageing through damage protection by the Arf/p53 pathway. Nature 448, 375-379. doi: 10.1038/nature05949

Mikkelsen, T. S., Ku, M., Jaffe, D. B., Issac, B., Lieberman, E., Giannoukos, G., et al. (2007). Genome-wide maps of chromatin state in pluripotent and lineagecommitted cells. Nature 448, 553-560. doi: 10.1038/nature06008

Mourikis, P., Sambasivan, R., Castel, D., Rocheteau, P., Bizzarro, V., and Tajbakhsh, S. (2012). A critical requirement for notch signaling in maintenance of the quiescent skeletal muscle stem cell state. Stem Cells 30, 243-252. doi: 10.1002/ stem. 775 
Murphy, M. M., Keefe, A. C., Lawson, J. A., Flygare, S. D., Yandell, M., and Kardon, G. (2014). Transiently active Wnt/ $\beta$-catenin signaling is not required but must be silenced for stem cell function during muscle regeneration. Stem Cell Rep. 3, 475-488. doi: 10.1016/j.stemcr.2014.06.019

Murphy, M. M., Lawson, J. A., Mathew, S. J., Hutcheson, D. A., and Kardon, G. (2011). Satellite cells, connective tissue fibroblasts and their interactions are crucial for muscle regeneration. Development 138, 3625-3637. doi: 10.1242/dev. 064162

Naito, A. T., Sumida, T., Nomura, S., Liu, M. L., Higo, T., Nakagawa, A., et al. (2012). Complement Clq activates canonical Wnt signaling and promotes aging-related phenotypes. Cell 149, 1298-1313. doi: 10.1016/j.cell.2012. 03.047

Oguro, H., Yuan, J., Ichikawa, H., Ikawa, T., Yamazaki, S., Kawamoto, H., et al. (2010). Poised lineage specification in multipotential hematopoietic stem and progenitor cells by the polycomb protein Bmil. Cell Stem Cell 6, 279-286. doi: 10.1016/j.stem.2010.01.005

Palacios, D., Mozzetta, C., Consalvi, S., Caretti, G., Saccone, V., Proserpio, V., et al. (2010). TNF/p38 $\alpha$ /polycomb signaling to Pax7 locus in satellite cells links inflammation to the epigenetic control of muscle regeneration. Cell Stem Cell 7, 455-469. doi: 10.1016/j.stem.2010.08.013

Paliwal, P., Pishesha, N., Wijaya, D., and Conboy, I. M. (2012). Age dependent increase in the levels of osteopontin inhibits skeletal muscle regeneration. Aging (Albany. NY) 4, 553-566.

Rathbone, C. R., Yamanouchi, K., Chen, X. K., Nevoret-Bell, C. J., Rhoads, R. P., and Allen, R. E. (2011). Effects of transforming growth factor-beta (TGF- $\beta 1$ ) on satellite cell activation and survival during oxidative stress. J. Muscle Res. Cell Motil. 32, 99-109. doi: 10.1007/s10974-011-9255-8

Raue, U., Slivka, D., Jemiolo, B., Hollon, C., and Trappe, S. (2006). Myogenic gene expression at rest and after a bout of resistance exercise in young (18-30 yr) and old (80-89 yr) women. J. Appl. Physiol. (1985) 101, 53-59. doi: 10.1152/ japplphysiol.01616.2005

Robson, L. G., Di, F., V, Radunovic, A., Bird, K., Zhang, X., and Marino, S. (2011). Bmil is expressed in postnatal myogenic satellite cells, controls their maintenance and plays an essential role in repeated muscle regeneration. PLoS ONE 6:e27116. doi: 10.1371/journal.pone.0027116

Rodier, F., and Campisi, J. (2011). Four faces of cellular senescence. J. Cell Biol. 192, 547-556. doi: 10.1083/jcb.201009094

Ross, J., Benn, A., Jonuschies, J., Boldrin, L., Muntoni, F., Hewitt, J. E., et al. (2012). Defects in glycosylation impair satellite stem cell function and niche composition in the muscles of the dystrophic Large(myd) mouse. Stem Cells 30, 2330-2341. doi: 10.1002/stem.1197

Roth, S. M., Martel, G. F., Ivey, F. M., Lemmer, J. T., Metter, E. J., Hurley, B. F., et al. (2000). Skeletal muscle satellite cell populations in healthy young and older men and women. Anat. Rec. 260, 351-358. doi: 10.1002/10970185(200012)260:4<350::AID-AR30>3.0.CO;2-6

Sambasivan, R., Yao, R., Kissenpfennig, A., Van, W. L., Paldi, A., Gayraud-Morel, B., et al. (2011). Pax7-expressing satellite cells are indispensable for adult skeletal muscle regeneration. Development 138, 3647-3656. doi: 10.1242/dev. 067587

Sanes, J. R. (2003). The basement membrane/basal lamina of skeletal muscle. J. Biol. Chem. 278, 12601-12604. doi: 10.1074/jbc.R200027200

Schaller, M. A., Logue, H., Mukherjee, S., Lindell, D. M., Coelho, A. L., Lincoln, P., et al. (2010). Delta-like 4 differentially regulates murine CD4 T cell expansion via BMI1. PLoS ONE 5:e12172. doi: 10.1371/journal.pone.0012172

Schuster-Gossler, K., Cordes, R., and Gossler, A. (2007). Premature myogenic differentiation and depletion of progenitor cells cause severe muscle hypotrophy in Delta1 mutants. Proc. Natl. Acad. Sci. U.S.A. 104, 537-542. doi: 10.1073/pnas. 0608281104

Shea, K. L., Xiang, W., LaPorta, V. S., Licht, J. D., Keller, C., Basson, M. A., et al. (2010). Sproutyl regulates reversible quiescence of a self-renewing adult muscle stem cell pool during regeneration. Cell Stem Cell 6, 117-129. doi: 10.1016/ j.stem.2009.12.015

Shefer, G., Van de Mark, D. P., Richardson, J. B., and Yablonka-Reuveni, Z. (2006). Satellite-cell pool size does matter: defining the myogenic potency of aging skeletal muscle. Dev. Biol. 294, 50-66. doi: 10.1016/j.ydbio.2006.02.022

Shinin, V., Gayraud-Morel, B., Gomes, D., and Tajbakhsh, S. (2006). Asymmetric division and cosegregation of template DNA strands in adult muscle satellite cells. Nat. Cell Biol. 8, 677-687. doi: 10.1038/ncb1425

Smith, Z. D., Chan, M. M., Humm, K. C., Karnik, R., Mekhoubad, S., Regev, A., et al. (2014). DNA methylation dynamics of the human preimplantation embryo. Nature 511, 611-615. doi: 10.1038/nature13581

Sousa-Victor, P., Gutarra, S., Garcia-Prat, L., Rodriguez-Ubreva, J., Ortet, L., RuizBonilla, V., et al. (2014). Geriatric muscle stem cells switch reversible quiescence into senescence. Nature 506, 316-321. doi: 10.1038/nature13013

Trensz, F., Haroun, S., Cloutier, A., Richter, M. V., and Grenier, G. (2010). A muscle resident cell population promotes fibrosis in hindlimb skeletal muscles of $\mathrm{mdx}$ mice through the Wnt canonical pathway. Am. J. Physiol. Cell Physiol. 299, C939-C947. doi: 10.1152/ajpcell.00253.2010

Troy, A., Cadwallader, A. B., Fedorov, Y., Tyner, K., Tanaka, K. K., and Olwin, B. B. (2012). Coordination of satellite cell activation and self-renewal by Parcomplex-dependent asymmetric activation of $\mathrm{p} 38 \alpha / \beta$ MAPK. Cell Stem Cell 11 , 541-553. doi: 10.1016/j.stem.2012.05.025

Vasyutina, E., Lenhard, D. C., Wende, H., Erdmann, B., Epstein, J. A., and Birchmeier, C. (2007). RBP-J (Rbpsuh) is essential to maintain muscle progenitor cells and to generate satellite cells. Proc. Natl. Acad. Sci. U.S.A. 104, 4443-4448. doi: 10.1073/pnas.0610647104

Verdijk, L. B., Snijders, T., Drost, M., Delhaas, T., Kadi, F., and van Loon, L. J. (2014). Satellite cells in human skeletal muscle; from birth to old age. Age (Dordr) 36, 545-547. doi: 10.1007/s11357-013-9583-2

Watanabe, S., Sato, K., Hasegawa, N., Kurihara, T., Matsutani, K., Sanada, K., et al. (2014). Serum C1q as a novel biomarker of sarcopenia in older adults. FASEB J. doi: 10.1096/fj.14-262154 [Epub ahead of print].

Zacks, S. I., and Sheff, M. F. (1982). Age-related impeded regeneration of mouse minced anterior tibial muscle. Muscle Nerve 5, 152-161. doi: 10.1002/mus. 880050213

Conflict of Interest Statement: The author declares that the research was conducted in the absence of any commercial or financial relationships that could be construed as a potential conflict of interest.

Received: 18 November 2014; accepted: 07 February 2015; published online: 20 February 2015

Citation: Parker MH (2015) The altered fate of aging satellite cells is determined by signaling and epigenetic changes. Front. Genet. 6:59. doi: 10.3389/fgene.2015.00059 This article was submitted to Epigenomics and Epigenetics, a section of the journal Frontiers in Genetics.

Copyright (C) 2015 Parker. This is an open-access article distributed under the terms of the Creative Commons Attribution License (CC BY). The use, distribution or reproduction in other forums is permitted, provided the original author(s) or licensor are credited and that the original publication in this journal is cited, in accordance with accepted academic practice. No use, distribution or reproduction is permitted which does not comply with these terms. 